Tourism in Analysis

DOI: http://dx.doi.org/10.11606/issn.1984-4867.v27i3p624-643

\title{
O Modesto Contributo do Turismo Rural no Douro, Portugal: um estudo baseado nos promotores e na oferta turística
}

\author{
The modest contribution of rural tourism in Douro, Portugal: a study based \\ on the promoters and touristic supply
}

La modesta contribución del turismo rural en la región del Douro, Portugal: un estudio basado en promotores y en la oferta turística

Maria Lúcia de Jesus Pato ${ }^{1}$

\begin{abstract}
Resumo
Este estudo tem como objetivo investigar as características e motivações dos promotores de turismo no espaço rural no Douro, bem como a oferta de atividades de animação turística proporcionada nos empreendimentos. Tendo com base um inquérito por questionário e estatísticas descritivas, evidencia-se que o produto turístico é desenvolvido principalmente por promotores com certo perfil socioeconómico: idade acima dos 45 anos, rendimento mensal elevado e pouca dedicação à unidade turística. Acresce que esses promotores, no geral, não têm formação na área turística e que antes de abrir o empreendimento não tinham qualquer experiência no ramo. A motivação principal para a criação do empreendimento terá sido a recuperação e preservação do património edificado. Adicionalmente, o estudo mostra que o turismo rural está ainda pouco enraizado na região, sendo escassas as atividades de animação turística baseadas nas tradições e cultura locais e as ligações à comunidade local. Conclui-se, pois, que o contributo para o desenvolvimento da região é modesto.
\end{abstract}

Palavras-chave: Turismo rural; Promotores; Oferta turística; desenvolvimento rural.

\begin{abstract}
This study aims to investigate the characteristics and motivations of the rural tourism promoters in Douro region, as well as the offer of tourist leisure activities developed in the housing units. Based in a survey and descriptive statistics, we argue that the tourist product is mostly developed by promoters with a certain profile: above the age of 45, with a high monthly income and very little dedication to the tourism unit. Moreover, these promoters, in general, do not have training in the tourism area and before opening the unit had no experience in the touristic field. The primary motivation for the creation of the tourist unit has been the recovery and preservation of the built heritage. Additionally, the study shows that rural tourism is still little rooted in the region, with scarce tourist entertainment activities based

\footnotetext{
Doutora em Turismo pela Universidade de Aveiro (UA), Portugal. Professora Adjunta no Instituto Politécnico de Viseu (IPV). Pesquisadora na Unidade de Investigação CI\&DETS do IPV e GOVCOOP da Universidade de Aveiro (UA), Portugal. Portugal. Aveiro, Aveiro, Brasil. E-mail: mljesus@sapo.pt
} 
Tourism in Analysis

on local culture and traditions and the links to the local community. It is therefore concluded that the contribution for region development is modest.

Keywords: Rural tourism; Promoters; Touristic supply; Rural development.

\section{Resumen}

Este estudio tiene como objetivo investigar las características y motivaciones de los promotores de turismo en las zonas rurales del Douro, Portugal, así como la realización de actividades de entretenimiento turísticas proporcionadas por las empresas de turismo. Con base en un cuestionario y en las estadísticas descriptivas, es evidente que el producto turístico está desarrollado principalmente por los promotores con determinado perfil socioeconómico: mayores de 45 años de edad, alto ingreso mensual y poca dedicación a la unidad de turismo. Por otra parte, estos promotores en general no tienen formación en el área de turismo y antes de abrir la empresa no tenían ninguna experiencia en el negocio. La principal motivación para la creación de la empresa ha sido la recuperación y conservación del patrimonio construido. Además, el estudio muestra que el turismo rural es todavía poco establecido en la región, con escasas actividades de entretenimiento turístico, basadas en las tradiciones locales y cultura y en los vínculos con la comunidad local. Por tanto, se llegó a la conclusión de que la contribución al desarrollo de la región es todavía modesta.

Palabras clave: Turismo rural; Promotores; Turismo; Desarrollo rural.

\section{Introdução}

Muitas das áreas rurais, sobretudo as mais periféricas e desfavorecidas, enfrentam hoje problemas graves em nível económico, social e outros. A crise dessas áreas está claramente associada ao declínio do setor agrícola e à falta de oportunidades em termos de emprego, o que, consequentemente, tem resultado num vertiginoso êxodo rural. Em Portugal, a situação descrita tem afetado sobretudo as regiões mais montanhosas e interiores do país, onde o êxodo tem levado ao abandono de muitos dos recursos locais (RIBEIRO; MARQUES, 2002).

$\mathrm{Na}$ procura por alternativas de desenvolvimento para essas áreas, o turismo rural surgiu e foi divulgado como uma oportunidade das populações diversificarem suas atividades económicas - em muitos casos dependentes da atividade agrícola -, criando assim uma fonte suplementar de receitas. Na verdade, em Portugal o turismo rural continua a ser apresentado e está associado, pelo menos do ponto de vista (mais) político, a uma série de benefícios não só económicos, mas também socioculturais e ambientais. Mas, se seu potencial é amplamente conhecido, as dúvidas acerca de seus reais benefícios subsistem. Como evidenciam vários autores (e.g. CÁNOVES et 
Tourism in Analysis

al., 2004; DISSART; AUBERT; TRUCHET, 2009; RIBEIRO; MARQUES, 2002; SHARPLEY, 2002), o desenvolvimento de atividades turísticas e de lazer em espaço rural, em termos práticos, não tem representado mais do que alternativas ténues de desenvolvimento, sendo que no caso concreto de Portugal não se tem constituído como um meio eficaz de desenvolvimento, mas beneficiado alguns atores e famílias (CAVACO, 1999; FIGUEIREDO, 2011).

Argumenta-se que a fragilidade do turismo rural em termos de desenvolvimento rural é devida à modéstia da oferta turística e ao ténue envolvimento das unidades turísticas com a comunidade local. De facto passadas quase três décadas da instituição legal do turismo no espaço rural (TER) em Portugal, muitos dos promotores continuam a adotar uma postura pouco ativa em termos de oferta de serviços de animação turística. Advoga-se ainda que por trás dessa postura comummente pouco ativa estão razões relacionadas ao perfil dos promotores de turismo e com as motivações que levaram à criação da unidade turística.

Tendo em conta a importância do turismo para o desenvolvimento das áreas rurais, o propósito deste artigo é apresentar o perfil socioeconómico dos promotores de TER, explorar as motivações de criação do empreendimento turístico e analisar a oferta em termos de atividades de animação turística proporcionada nos respetivos empreendimentos. Para tal, foi aplicado um inquérito por questionário a promotores de TER de uma região rural com claros sinais de pobreza, mas detentora de um património singular: o Douro. Parte da região em estudo foi, aliás, classificada pela Organização das Nações Unidas para a Educação, a Ciência e a Cultura (Unesco) como Património Mundial da Humanidade.

Este artigo está dividido em cinco partes, respectivamente: introdução; revisão da literatura; metodologia de investigação; análise e discussão dos dados; e conclusões.

\section{Revisão da literatura}

\subsection{Contributo do turismo rural para o desenvolvimento rural}

Mercê dos problemas das áreas rurais, o conceito de "desenvolvimento rural" está cada vez mais na agenda de diversas entidades, contudo, é difícil definí-lo e, por isso, ele tem sido alvo de diferentes interpretações. Muito provavelmente, o ponto onde todas essas interpretações concordam reside no facto de se reconhecer que o desenvolvimento rural 
não se esgota na agricultura, sendo muito mais que a produção agrícola e/ou a produção de alimentos. Com efeito, a questão do desenvolvimento rural deve centrar-se não só nas funções tradicionais, mas, também, nas novas funções das áreas rurais e, como tal, na diversificação de atividades e na multifuncionalidade da agricultura.

É nesse contexto que se salienta uma das facetas relativas ao potencial do turismo rural. Enquanto atividade transversal, "constitui uma atividade geradora de desenvolvimento económico para o mundo rural, quer por si só, quer através da dinamização de muitas outras atividades económicas que dele são tributárias e que com ele interagem" (DGADR, [s.d.]). De absolutamente ausente nos planos e propostas de desenvolvimento rural das décadas de 1960 e 1970, o turismo passou a aglutinar grande parte da atenção dada pelas entidades públicas e (mesmo) privadas, sendo encarado como um mecanismo de rendimento e emprego, particularmente nas áreas rurais periféricas onde a atividade agrária está em declínio e crise (SHARPLEY, 2002). Seja no campo histórico, da cultura, do desporto e aventura, da saúde, de orientação educativa, do lazer e em outros domínios, são imensas as possibilidades que as áreas rurais podem proporcionar em termos turísticos.

Isso torna também imensas as oportunidades e alternativas económicas que podem vir a concretizar-se para desenvolver tais ofertas, sendo exemplo disso as ofertas a desenvolver em empreendimentos de turismo localizados em áreas rurais. Assim, as repercussões favoráveis que tais iniciativas podem projetar a nível económico são promissoras ao nível do número de postos de trabalho que elas podem vir a criar, mas também por seu carácter tradicional e, ao mesmo tempo, inovador, e como tal, pela qualificação de muitas das profissões que elas suscitam e exigem (RIBEIRO; MERGULHÃO, 2000).

Sob o ponto de vista sociocultural o turismo rural aumenta a consciência para a necessidade de preservação e desenvolvimento da cultura local, podendo também fortalecer a identidade cultural de um território (KOMPPULA; RHODRI; MARCJANNA, 2007). Para além disso, a atividade tem se revelado importante no que diz respeito ao papel da mulher na dinamização do negócio turístico (MCGEHEE; KIM; JENNINGS, 2007). Acresce ainda que, o turismo rural tem permitido a manutenção de laços com a propriedade e com a terra por parte de um conjunto de pessoas que frequentemente ocuparam um lugar de destaque na história desses lugares e que, de outra forma, dificilmente residiriam nos meios rurais (SILVA, 2005/2006). A propósito da identidade cultural dos territórios, o turismo rural tem ainda a virtude de contribuir para 
Tourism in Analysis

a preservação da gastronomia tradicional local (Ibidem; CRISTÓVÃO; TIBÉRIO; ABREU, 2008).

Uma das outras valências do turismo rural consiste na recuperação de inúmeros imóveis degradados e obsoletos, incluindo solares e casas apalaçadas e, sobretudo, casas rústicas (FERREIRA, 2004; SILVA, 2005/2006). A recuperação desse património edificado constitui-se em algumas regiões (como é o caso das regiões rurais portuguesas) como uma mais-valia do turismo rural, na medida em que mantém a habitabilidade nas regiões rurais e permite a recuperação de valores patrimoniais, sobretudo se tivermos em conta que parte desses imóveis tem séculos de existência. Para além disso, o turismo rural contribui para a manutenção das paisagens parcialmente humanizadas, celebradas pelo desejo pastoral perfilhado por uma parte significativa das populações citadinas (SILVA, 2007).

Por aquilo que se disse anteriormente, concorda-se com Roberts e Hall (2003) e Sharpley (2002) que referem que os contributos do turismo rural podem ser de três tipos:

- Económicos: crescimento económico e diversificação da economia rural; criação de emprego, oportunidades para o aumento de rendimentos através da pluriatividade; e criação de novos mercados para produtos agrícolas e outros produtos locais;

- Socioculturais: desenvolvimento sociocultural, incluindo a manutenção e a dinamização dos serviços públicos; a revitalização do artesanato local, costumes e identidade cultural; e oportunidade para contactos sociais e "partilha de culturas";

- Ambientais: proteção e melhoria da paisagem natural construída e das infraestruturas locais.

\subsection{Turismo e desenvolvimento económico das áreas rurais?}

O turismo em áreas rurais tem sido ativamente promovido como a panaceia para os problemas das áreas rurais (RIBEIRO; MARQUES, 2002). Contudo, a investigação feita em vários países europeus tem mostrado que, embora a atividade possa contribuir para o desenvolvimento rural, ela não é o "motor de desenvolvimento" das áreas rurais, tampouco a solução para seus problemas (CÁNOVES et al., 2004). No campo económico, as evidências empíricas sugerem que, de facto, seu impacto é limitado já que os visitantes têm tendência a se envolverem em poucas atividades no meio rural e seus gastos tendem a ser relativamente baixos (BEL et al., 2015; RIBEIRO; MARQUES, 2002). 
Tourism in Analysis

A pouca envolvência dos visitantes em atividades recreativas em nível local cruza-se certamente com a falta de oportunidades para tal, o que, por sua vez, pode estar relacionado com as motivações de criação dos empreendimentos turísticos e com o perfil socioeconómico dos promotores. Em Portugal vários autores (e.g. JOAQUIM, 1999; MESQUITA, 2009; PATO, 2012; SILVA, 2005/2006) notam que a motivação principal para a instalação de empreendimentos de turismo rural relaciona-se com "a estratégia de recuperação e conservação do património pessoal ou familiar" dos promotores, normalmente pertencentes a famílias com recursos patrimoniais, e não com uma estratégia de diversificação da atividade agrícola e, consequentemente, da economia rural. Acaba por ser, frequentemente, esse o contexto, que faz que o setor de turismo rural não se encontre devidamente articulado com outros produtos e serviços turísticos, como é o caso da restauração e não contribua para a criação de empregos - quer diretos, quer indiretos (cf. SILVA, 2005/2006).

Cristóvão (1999) e Moreira (1994) falam, aliás, da elitização da atividade turística, de sua frequente falta de complementaridade com as atividades agrícolas e de seu fraco enraizamento na economia e cultura local. Compreende-se assim que os efeitos do turismo rural, no contexto atual, parecem não representar mais do que ténues alternativas de desenvolvimento dos meios rurais, particularmente em Portugal (FIGUEIREDO, 2011).

\section{Metodologia}

\subsection{Justificação e apresentação do caso de estudo}

A região do Douro (RD), é uma sub-região portuguesa, parte da região norte de Portugal, integrando os distritos de Bragança, Vila Real, Viseu e Guarda. A região é atravessada pelo rio que nasce em Espanha e que lhe dá o nome - o rio Douro. A área de $4.112 \mathrm{~km}^{2}$ integra 19 concelhos (INE, 2012).

Por seu posicionamento geográfico, os concelhos apresentam características próprias de regiões do interior, nomeadamente em termos demográficos e económicos.

A região foi escolhida para estudo devido ao facto de ser uma região interior, com reduzida densidade populacional (INE, 2012) e poucas oportunidades de emprego e condições de vida. Com efeito, possui um produto interno bruto (PIB) abaixo da média nacional (Idem, 2010) assim como um "Poder de Compra" abaixo da média nacional (Idem, 2009). 
No entanto, a região apresenta um potencial enorme em termos turísticos. Para além de parte da região em estudo ser Património Mundial da Humanidade pela Unesco desde 2001 e, como tal, possuir um conjunto de recursos turísticos diversificados e diferenciadores (rio Douro, paisagens naturais, património histórico e arquitetónico, entre outros), o Douro foi considerado um polo de desenvolvimento turístico do país pelo Turismo de Portugal (PORTUGAL, 2006). Paralelamente, o Douro tem vindo a ser pioneiro na integração em redes de referência mundial. Com efeito, a região figura entre as melhores regiões turísticas do mundo, tendo integrado os Destinos Turísticos de Excelência Mundial da Organização Mundial de Turismo (OMT) em 2008. Com efeito, de catorze categorias que o Centro Mundial de Destinos de Excelência (CED) avaliou naquele ano, sete obtiveram a classificação de excelência - Ambiente e Paisagem, Cultura e Património, Segurança, Vinhas, Transportes, Saúde e Bem-Estar, Alimentação e Bebidas) - e duas, um desempenho elevado - Arqueologia e Informações e Acolhimento (CCDRN, 2009).

Ao mesmo tempo o Douro está associado à National Geographic (o Douro foi o primeiro destino nacional a aderir à rede), tendo sido eleito pela National Geographic Society o sétimo melhor destino mundial para Turismo Sustentável (Idem, 2013). Há dois anos, a Fodor 's - considerada o maior grupo de publicações de turismo do mundo - elegeu também o vale do Douro como um dos vinte e cinco destinos obrigatórios a visitar naquele ano.

\subsection{Procedimentos metodológicos}

Este trabalho é o resultado de uma investigação mais abrangente, inserida num projeto de doutoramento financiado pela Fundação para a Ciência e Tecnologia (FCT). Os dados acerca dos promotores e caracterização dos respetivos empreendimentos de turismo rural foram recolhidos com base num inquérito por questionário aplicado em 2010. O guião do inquérito foi construído com base na revisão da literatura, sendo que sua estrutura teve em conta o facto de ser administrado presencialmente pelo investigador, o propósito do estudo e o tipo de questões mais adequadas, incluindo questões fechadas, abertas, escolha múltipla e em escala de Likert. Esta apresentava cinco possibilidades de resposta, sendo que 1 representava nada importante; 3, importante; e 5, extremamente importante. 
Tourism in Analysis

Embora fosse nossa intenção aplicar o inquérito por questionário a todos os promotores de empreendimentos de TER da região em análise (no total de 85 ), devido à indisponibilidade por parte dos promotores de tais empreendimentos, foram aplicados 44 inquéritos a empreendimentos de TER, nas modalidades de turismo rural, turismo de habitação, agroturismo, casas de campo, hotéis rurais e turismo de aldeia.

À data da realização do inquérito, a classificação do TER nessas modalidades tinha a ver com o tipo de construção em causa e com outros requisitos dos empreendimentos em questão. De forma genérica, o serviço de alojamento e animação a turistas nos empreendimentos de turismo de habitação, turismo rural e agroturismo era desenvolvido em empreendimentos de maior exigência em termos de construção, mobiliário e decoração, sendo que a modalidade de agroturismo apenas poderia ser desenvolvida em explorações agrícolas, permitindo, assim, aos turistas, o acompanhamento e a participação nas atividades agrícolas. As casas de campo e o turismo de aldeia são, como se inferiu anteriormente, modalidades do TER menos exigentes em termos de construção, mobiliário e decoração, sendo que o turismo de aldeia apenas poderia ser desenvolvido quando um conjunto de no mínimo cinco casas situadas numa aldeia fossem exploradas de forma integrada por uma única entidade ou promotor singular. Por sua vez, os hotéis rurais diferenciam-se das anteriores modalidades, porque possuem já um carácter de estabelecimento hoteleiro, devendo, contudo, por sua traça e materiais de construção, respeitar igualmente as características dominantes das regiões rurais onde se encontram localizados.

A última fase do estudo envolveu a análise dos dados. Assim, recorrendo-se a estatísticas descritivas, os dados foram tratados com base no software Package for the Social Sciences (SPSS) versão 20 .

\section{Discussão dos resultados}

\subsection{O perfil dos promotores de TER}

Na Tabela 1 observa-se que a maioria dos promotores (40,9\% e 29,6\%) de TER da região possui idade superior a 65 anos ou tem entre 45 e 54 anos de idade. A larga maioria $(79,5 \%)$ encontra-se ainda em situação profissional ativa. No entanto, em termos das profissões exercidas é de sublinhar: (1) o elevado padrão socioeconómico que a descriminação das 
Tourism in Analysis

profissões dos promotores nos sugerem e, (2) a pouca ligação à agricultura, sendo menos de $10 \%$ aqueles que têm a agricultura como atividade económica principal.

Outra componente, que igualmente nos importa destacar (e que se encontra ligada à anterior), diz respeito ao grau de instrução dos promotores, sendo que metade deles possui formação superior. Contudo, nenhum dos promotores em causa possui formação académica na área do turismo e apenas uma pequena percentagem (6,8\%) possui formação profissional na área. Podemos ainda avançar que, em sua maioria (79,5\%) os promotores não possuíam experiência turística antes de abrir o empreendimento.

Para a larga maioria dos promotores $(88,6 \%)$, a fonte principal de rendimentos do agregado doméstico é exterior ao empreendimento turístico: ou do emprego, ou então das reformas elevadas de que normalmente são portadores. Julgamos, aliás, que essa questão (a par da atividade económica) é também causa e consequência do pouco tempo dedicado à atividade no empreendimento. Com efeito, mais de metade dos promotores diz dedicar menos de $25 \%$ de tempo semanal na unidade turística.

Tabela 1 - Caracterização sociodemográfica e profissional dos promotores de TER

\begin{tabular}{|l|c|c|}
\hline & n & \% \\
\hline Idade (anos) & & \\
\hline$<34$ & 2 & 4,5 \\
\hline $35-44$ & 1 & 2,3 \\
\hline $45-54$ & $\mathbf{1 8}$ & $\mathbf{4 0 , 9}$ \\
\hline $55-64$ & 10 & 22,7 \\
\hline$>65$ anos & 13 & 29,6 \\
\hline Grau de instrução & & \\
\hline $1^{{ }^{\circ}}$ ciclo (1-4 anos) & 6 & 13,6 \\
\hline $2^{{ }^{\circ}}$ ciclo (5-6 anos) & 1 & 2,3 \\
\hline $3^{{ }^{\circ}}$ ciclo (7-9 anos) & 3 & 6,8 \\
\hline Secundário geral & 9 & 20,5 \\
\hline Superior & $\mathbf{2 2}$ & $\mathbf{5 0}$ \\
\hline Outra situação & 1 & 2,3 \\
\hline NS/NR & 2 & 4,5 \\
\hline Situação na profissão & & \\
\hline Ativo & $\mathbf{3 5}$ & $\mathbf{7 9 , 5}$ \\
\hline Não ativo & 9 & 20,5 \\
\hline
\end{tabular}


Tourism in Analysis

Tabela 1 - Continuação

\begin{tabular}{|c|c|c|}
\hline & n & $\%$ \\
\hline \multicolumn{3}{|l|}{ Profissão } \\
\hline $\begin{array}{l}\text { Quadros superiores da administração pública, dirigentes e quadros superiores de } \\
\text { empresas }\end{array}$ & 22 & 50 \\
\hline Especialistas de profissões intelectuais e científicas & 6 & 13,6 \\
\hline Técnicos e profissionais de nível intermédio & 1 & 2,3 \\
\hline Pessoal administrativo e similares & 2 & 4,5 \\
\hline Agricultores & 4 & 9,1 \\
\hline NA & 9 & 20,5 \\
\hline \multicolumn{3}{|l|}{ Tempo semanal despendido com o empreendimento } \\
\hline$<25 \%$ & 23 & 52,3 \\
\hline $25-50 \%$ & 7 & 15,9 \\
\hline $51-75 \%$ & 5 & 11,4 \\
\hline $76-99 \%$ & 7 & 15,9 \\
\hline $100 \%$ & 2 & 4,5 \\
\hline \multicolumn{3}{|l|}{ Fonte principal de rendimentos } \\
\hline Empreendimento & 5 & 11,4 \\
\hline Exterior empreendimento & 39 & 88,6 \\
\hline \multicolumn{3}{|l|}{ Rendimento líquido agregado doméstico (em euros) } \\
\hline$<500$ & 1 & 2,3 \\
\hline $500-1500$ & 12 & 27,3 \\
\hline $1501-2500$ & 4 & 9,1 \\
\hline $2501-3500$ & 7 & 15,9 \\
\hline $3501-4500$ & 3 & 6,8 \\
\hline$>4500$ & 15 & 34,1 \\
\hline NS/NR & 2 & 4,5 \\
\hline \multicolumn{3}{|l|}{ Formação em turismo (profissional) } \\
\hline Sim & 3 & 6,8 \\
\hline Não & 41 & 92,2 \\
\hline \multicolumn{3}{|l|}{ Experiência turística antes abrir o empreendimento } \\
\hline Sim & 8 & 18,2 \\
\hline Não & 35 & 79,5 \\
\hline NS/NR & 1 & 2,3 \\
\hline
\end{tabular}

Fonte: Dados da pesquisa. 
Tourism in Analysis

Pela observação do escalão de rendimentos, corroboramos ainda a (possível) pertença dos promotores a estratos socioeconómicos médios a médios altos. É efetivamente de destacar que grande parte dos promotores aqui em causa refere usufruir de um rendimento mensal líquido superior a 4.500 euros.

A grande ilação que se pode tirar desta análise, tal como indiciam vários autores (CAVACO, 1995; CRISTÓVÃO, 1999; MOREIRA, 1994) há cerca de duas décadas atrás é que, no geral, o turismo rural é ainda uma atividade que começou pelo topo da pirâmide social e continua longe de se estender a estratos sociais mais baixos e aos agricultores e proprietários rurais. Temos mesmo para nós que, esse facto é, à luz dos objetivos de desenvolvimento rural que são normalmente atribuídos ao TER por muitas autoridades públicas e privadas a nível nacional, a característica mais paradoxal do turismo rural em Portugal (JESUS; KASTENHOLZ; FIGUEIREDO, 2012).

\subsection{Motivações de criação do empreendimento turístico}

As respostas acerca das motivações de criação da unidade turística foram codificadas e apresentadas em grupos. Conforme se observa na Tabela 2, a larga maioria dos promotores (70,5\%) refere razões relativas à recuperação/dinamização da herança família. Apenas uma pequena percentagem de promotores $(15,4 \%)$ refere motivações de abertura do empreendimento relativas à diversificação da atividade económica.

Tabela 2 - Motivações de abertura do empreendimento

\begin{tabular}{|l|c|c|}
\hline Motivos & $\mathbf{n}$ & $\mathbf{\%}$ \\
\hline Recuperar/dinamizar herança familiar & $\mathbf{3 1}$ & $\mathbf{7 0 , 5}$ \\
\hline Diversificar a atividade económica & $\mathbf{1 0}$ & $\mathbf{1 5 , 4}$ \\
\hline Ocupação durante a reforma & 2 & 3,1 \\
\hline Independência & 5 & 6,3 \\
\hline Recuperar dívida pelo património adquirido & 2 & 3,1 \\
\hline Outras razões & 16 & 36,4 \\
\hline
\end{tabular}

Fonte: Dados da pesquisa.

Esses resultados indiciam que, tal como sugerido por vários autores (e.g. JOAQUIM, 1999; MESQUITA, 2009; PATO, 2012; SILVA, 2005/2006) noutros contextos, a motivação 
Tourism in Analysis

principal para a instalação das unidades de TER no Douro está relacionada com a "estratégia de recuperação e conservação do património pessoal ou familiar" dos promotores e não com questões relativas à diversificação da atividade económica e tampouco de desenvolvimento rural.

\subsection{Atributos mais valorizados no turismo rural: a perspetiva dos promotores}

Uma vez que nos movemos num universo onde a existência de determinados atributos no empreendimento depende dos promotores, quisemos saber o grau de importância que eles atribuem aos requisitos que, de modo geral, a literatura considera como importantes no turismo rural. Assim, pedimos aos promotores que assinalassem aqueles que consideram ser os três atributos principais do TER. Dentre os mais valorizados pelos promotores estão o contacto com a natureza, o contacto com a cultura e tradições e a tranquilidade e o descanso proporcionado.

Gráfico 1 - Atributos valorizados pelos promotores de TER

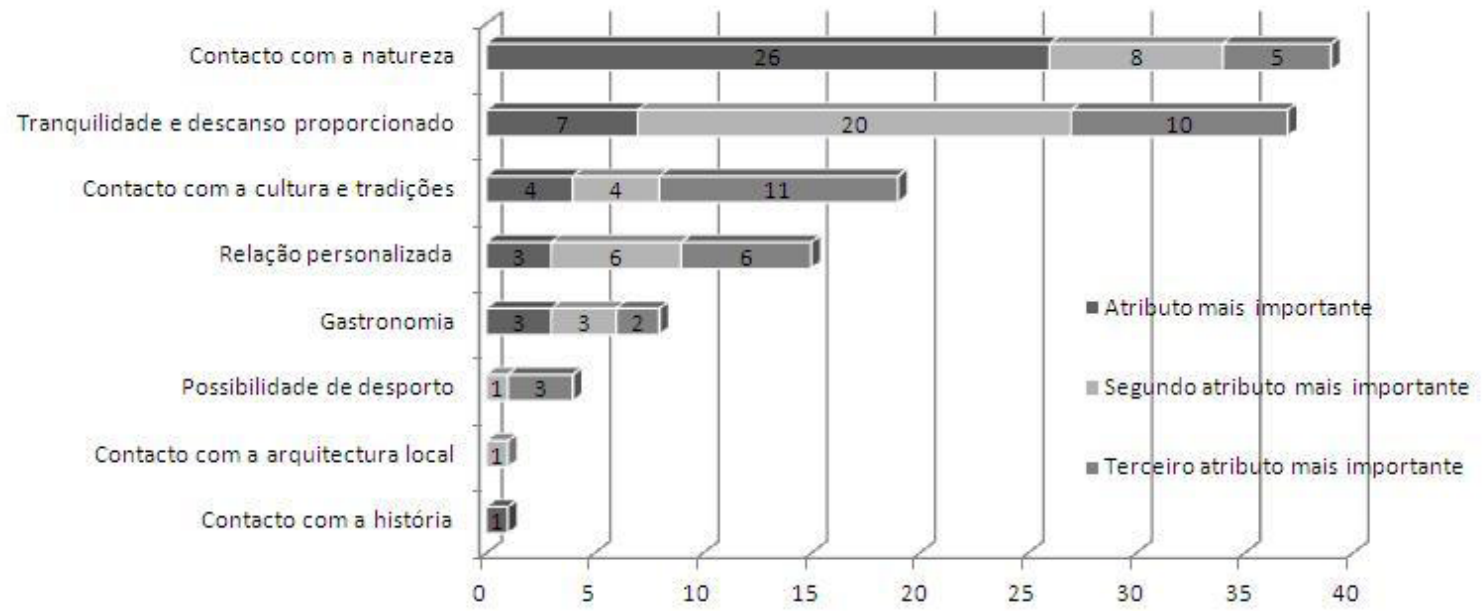

Fonte: Dados da pesquisa.

Apresentámos ainda aos inquiridos um conjunto de afirmações acerca de determinados atributos do empreendimento turístico, pedindo aos promotores que assinalassem a importância que atribuem a eles. Os requisitos ou serviços básicos do empreendimento - como casa de banho por quarto, tranquilidade e descanso e pessoas capazes de orientar os turistas 
sobre as atividades a realizar - foram os atributos mais valorizados pelos promotores de TER, com 4,6, 4,4 e 4,2 de média, respetivamente.

Tabela 3 - Atributos valorizados pelos promotores de TER no turismo rural

\begin{tabular}{|l|c|c|c|c|c|c|}
\hline Atributos & $\mathbf{1}$ & $\mathbf{2}$ & $\mathbf{3}$ & $\mathbf{4}$ & $\mathbf{5}$ & Média \\
\hline Casa de banho por quarto & 0,0 & 2,3 & 6,8 & 27,3 & 63,6 & 4,6 \\
\hline Tranquilidade e descanso & 0,0 & 0,0 & 13,6 & 36,4 & 50,0 & 4,4 \\
\hline $\begin{array}{l}\text { Pessoas capazes de orientar turistas sobre atividades } \\
\text { a realizar }\end{array}$ & 0,0 & 0,0 & 13,6 & 56,8 & 29,6 & 4,2 \\
\hline Sistema de aquecimento e refrigeração & 0,0 & 0,0 & 25,0 & 54,5 & 20,5 & 4,0 \\
\hline Decoração acolhedora e em harmonia com o espaço & 0,0 & 0,0 & 38,6 & 38,6 & 22,8 & 3,9 \\
\hline Piscina & 0,0 & 9,3 & 23,3 & 48,8 & 18,6 & 3,8 \\
\hline Relação familiar e personalizada & 0,0 & 16,3 & 34,9 & 25,6 & 23,2 & 3,6 \\
\hline Atividades de lazer & 0,0 & 23,3 & 34,9 & 39,5 & 2,3 & 3,2 \\
\hline Acesso à Internet & 0,0 & 34,1 & 25,0 & 36,4 & 4,5 & 3,1 \\
\hline Cozinha equipada & 0,0 & 38,6 & 25,0 & 29,6 & 6,8 & 3,0 \\
\hline Lareira & 0,0 & 25,0 & 50,0 & 25,0 & 0,0 & 3,0 \\
\hline Oferta de refeições & 0,0 & 31,8 & 43,2 & 18,2 & 6,8 & 3,0 \\
\hline Televisão & 0,0 & 38,6 & 40,9 & 18,2 & 2,3 & 2,8 \\
\hline Quarto para pessoas com dificuldades motoras & 2,3 & 40,9 & 38,6 & 15,9 & 2,3 & 2,7 \\
\hline
\end{tabular}

Nota: Média calculada com base numa escala de Likert sendo que 1 representa nada importante; 3, importante; e 5, extremamente importante.

Fonte: Dados da pesquisa.

É de ressalvar que as eventuais atividades de lazer apenas alcançam uma importância relativa $(3,2)$ - o que não é de se admirar, uma vez que os esforços em proporcionar tais atividades sejam apenas medianos. Se a animação pode concorrer decisivamente para a diferenciação da unidade turística, sua débil oferta poderá constituir um constrangimento a seu desenvolvimento, sobretudo numa época em que os turistas deixaram de procurar apenas um local de descanso e evasão do quotidiano, deslocando-se também motivados pela prática de outras atividades que justifiquem a permanência na unidade turística e região.

Dos requisitos menos valorizados pelos promotores, com apenas uma média de 2,7, está ainda o referente ao quarto para pessoas com dificuldades motoras. Esse é certamente um campo nos quais os promotores de TER devem encetar esforços. 
Tourism in Analysis

\subsection{Características da oferta de animação turística}

Uma vez que, cada vez mais, não é o desejo de descanso ou a necessidade de dormir que são causais para o consumo turístico, mas a procura das características da unidade turística e do destino em seu todo (PATO, 2012), quisemos então analisar as atividades de animação turística colocadas a serviço dos turistas. Assim, a par do alojamento, que inclui obrigatoriamente o serviço de pequeno-almoço, à partida parecia existir em muitas casas um conjunto de outros serviços e atividades de animação à disposição dos turistas.

Constatamos que no topo de lista encontra-se o serviço de refeições, proporcionado por 61,4\% das unidades de TER (Gráfico 2). Esse serviço de refeições é, no entanto, frequentemente condicionado pelo número de pessoas e pela duração de sua estadia (que deve ser igual ou superior a duas noites) e requer marcação prévia. Existe ainda, em mais de metade das unidades, um conjunto de outras atividades que os turistas podem usufruir. Citam-se a este respeito as relativas ao descanso na piscina e aos passeios de bicicleta, proporcionadas em mais de metade dos empreendimentos analisados.

Apesar dessa oferta, observamos igualmente que as atividades que à partida caracterizam as regiões e a cultura local são escassas e estão pouco desenvolvidas. Com efeito, observamos que menos de metade dos empreendimentos oferece provas de vinhos e apenas uma percentagem modesta de promotores oferece atividades relacionadas com a observação de atividades agrícolas, sendo parcas ou nulas as atividades relacionadas com cantares e danças tradicionais, com o património, a história e a cultura local. Vale a pena sublinhar neste ponto que, parte da região em análise é Património Mundial da Humanidade resultante de um processo multissecular de adaptação de técnicas e saberes específicos de cultivo da vinha e também a primeira região Demarcada do Mundo em termos vitivinícolas. Seria por isso de esperar uma maior dinamização de atividades lúdico-culturais deste âmbito. 
Tourism in Analysis

Gráfico 2 - Atividades proporcionadas nos empreendimentos de TER

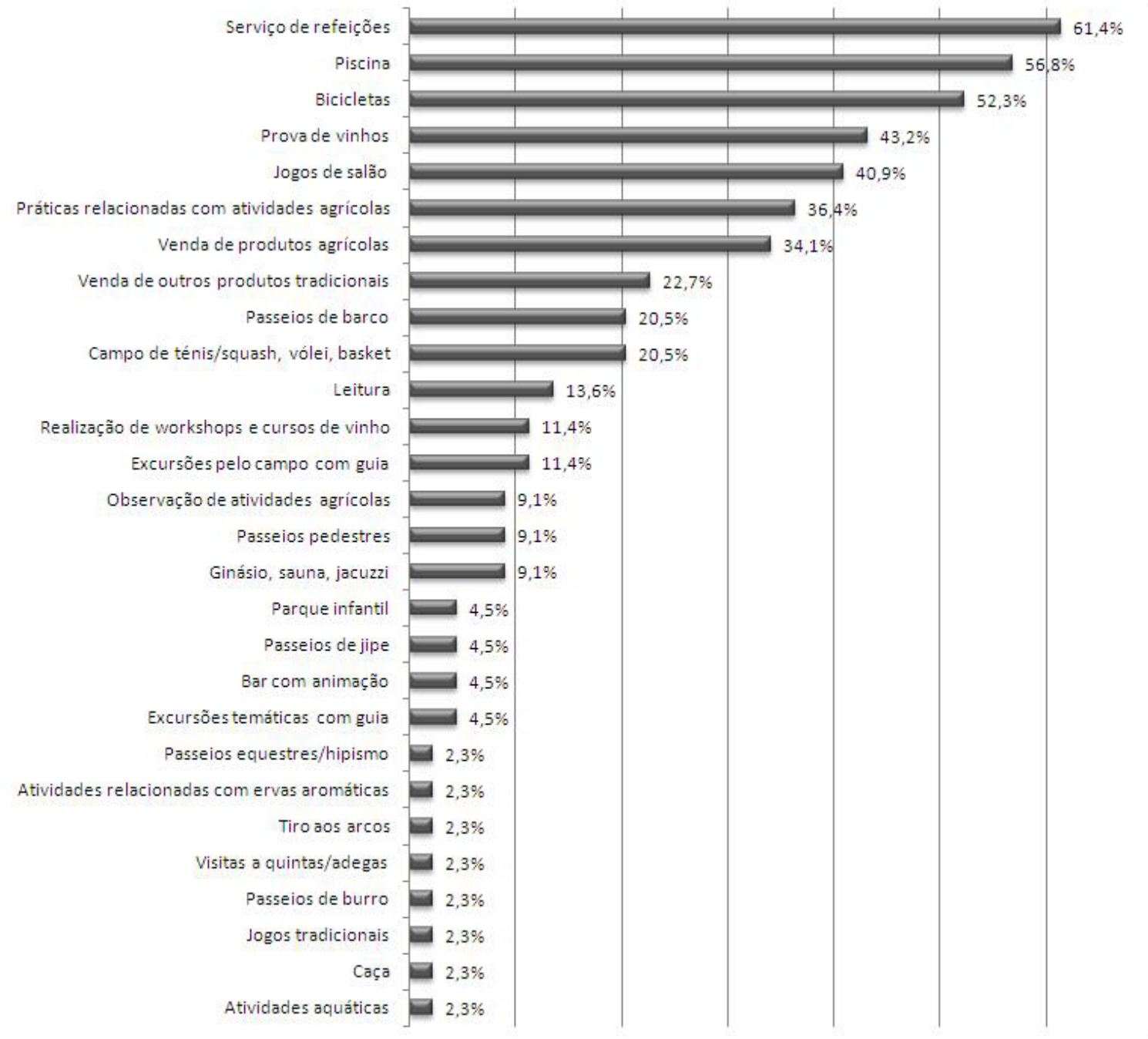

Fonte: Dados da pesquisa.

Acresce ainda que a maioria dessas atividades de animação é essencialmente desenvolvida dentro da propriedade de inserção das unidades de TER. Diante desse contexto, não é de estranhar que as ligações entre os promotores dos empreendimentos e outras entidades em nível regional ou local sejam também ténues. Efetivamente, conforme a Gráfico 3, a maioria dos promotores (66\%) afirma que não são estabelecidas quaisquer ligações com as entidades locais/regionais em termos do fornecimento de bens e serviços ao empreendimento turístico. Para além desse facto, constatámos ainda que, no caso do estabelecimento de ligações com entidades exteriores para fornecimento de bens e serviços ao empreendimento, estas revestem um carácter informal e esporádico. 
Tourism in Analysis

Gráfico 3 - Ligações estabelecidas com fornecedores de bens e serviços ao empreendimento (3A) e com outras entidades com vista ao desenvolvimento do empreendimento de TER (3B)
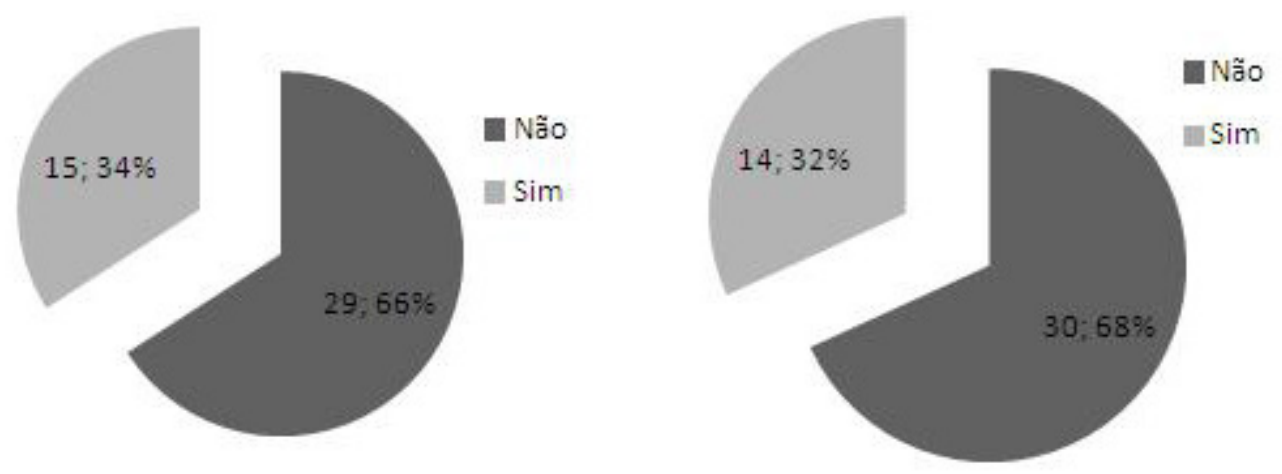

Fonte: Dados da pesquisa.

Ainda conforme a Gráfico 3, a maioria dos promotores (68\%) afirma ainda não colaborar com outro tipo de entidades (como câmaras, associações locais de desenvolvimento e entidades regionais de turismo) com vista ao desenvolvimento do empreendimento turístico. Assim e apesar de alguns exemplos notáveis que tivemos oportunidade de observar in loco, tal como afirmado por Cristóvão, Tibério e Abreu (2008), no geral, a oferta não está ainda preparada para responder a novas procuras.

\section{Conclusões}

Neste estudo evidenciámos algumas das características socioeconómicas dos promotores de TER, as motivações de abertura ao turismo e as características da oferta turística dos empreendimentos turísticos na região do Douro. No que diz respeito ao perfil sociodemográfico dos promotores observámos que, em sua maioria, são pessoas com uma idade bem definida, possuem um nível de formação académica superior (contrastando com a maioria dos residentes da região) e possuem um rendimento mensal líquido do agregado doméstico desafogado (proveniente, sobretudo, de atividades exteriores ao empreendimento turístico) - tanto mais se o compararmos com os rendimentos mensais líquidos dos pequenos agricultores da região. Daí que argumentamos que passadas quase três décadas da instituição legal do TER em Portugal, tal como proferido por Cristóvão (1999) o turismo rural é (e continuará 
certamente a ser) no país uma atividade (bastante) elitizada e não acessível à maioria dos habitantes das áreas rurais. Acresce ainda que mais de metade dos promotores do TER diz dedicar pouco tempo à gestão do empreendimento (especificamente menos de $25 \%$ de seu tempo), não ter formação na área turística e não ter tido qualquer experiência no ramo (turístico) antes de abrir a unidade.

A motivação principal para a criação da unidade turística está relacionada à recuperação e preservação do património edificado e não tanto com as questões de dinamização da atividade económica e/ou questões relativas ao desenvolvimento rural. Em nosso entender, a par do perfil sociodemográfico dos promotores, as motivações de criação do empreendimento turístico - especificamente a motivação essencialmente focada na recuperação do património edificado (geralmente em estado degradado) - ajudam a explicar a modéstia em termos de atividades de animação turística. De facto, uma análise mais detalhada dessa oferta mostra que ela é escassa e debilmente desenvolvida pela maioria dos promotores que integram a amostra, tendo também um fraco enraizamento a nível local. A confirmá-lo está o facto de apenas uma percentagem muito reduzida de empreendimentos oferecer atividades tradicionais, como a observação de danças e cantares tradicionais, o artesanato, os jogos populares, entre outras atividades. Por essa razão, não é de estranhar o ténue e esporádico envolvimento com a comunidade local e com os fornecedores de bens e serviços locais. Daí que atestamos que o sistema de funcionamento em rede, que para alguns autores (e.g. CRISTÓVÃO, 2011; MURDOCH, 2000) é condição de desenvolvimento local e regional, na região em apreço é praticamente inexistente.

Apesar da modéstia da oferta de atividades de animação turística e ao ténue envolvimento das unidades turísticas com a comunidade local, não se deve, contudo, ignorar que os promotores estão a investir na recuperação e preservação do património edificado, havendo por essa via um ganho para a região do Douro. Por outro lado, nesse universo de promotores - embora em número reduzido, é certo - também existem promotores que adotam uma postura mais ativa e tentam ter um produto turístico mais completo e diversificado, assim como estabelecer mais ligações com a comunidade local.

Em termos de trabalho futuro, a fim de compreendermos as atitudes e os comportamentos dos promotores, seria interessante complementar esses dados com uma análise mais qualitativa, através, por exemplo, de triangulação dos dados. 
Tourism in Analysis

\section{Referências}

BEL, F. et al. Domestic demand for tourism in rural areas: insights from summer stays in Three French Regions. Tourism Management, Amsterdam, v. 46, p. 562-570, 2015.

CÁNOVES, G. et al. Rural tourism in Spain: an analysis of recent evolution. Geoforum, Amsterdam, v. 35, n. 6, p. 755-769, 2004.

CAVACO, C. Turismo rural e desenvolvimento local. In: . (Ed.). As regiões de fronteira: estudos para o desenvolvimento rural e urbano. Lisboa: Centro de Estudos Geográficos da Universidade de Lisboa, 1995. p. 351-408.

. Turismo rural e turismo de habitação em portugal. In: (Ed.). Desenvolvimento rural desafio e utopia. Lisboa: Centro de Estudos Geográficos da Universidade de Lisboa, 1999. p. 293-318.

CCDRN - COMISSÃO DE COORDENAÇÃO E DESENVOLVIMENTO REGIONAL DO NORTE. Estrutura de missão do Douro relatório da atividade desenvolvida e dos resultados alcançados. Peso Da Régua: CCDRN, 2013.

Turismo na região do norte de Portugal. Porto: Observatório das Dinâmicas Regionais do Norte; CCDRN, 2009.

CRISTÓVÃO, A. Acção colectiva e turismo em espaço rural: as rotas do vinho e do azeite no Douro e Trás-os-Montes, Portugal. In: SOUZA, M. D.; ELESBÃO, I. (Eds.). Turismo rural: iniciativas e inovações. Porto Alegre: UFRGS, 2011. p. 101-141.

. Ambiente e desenvolvimento de áreas rurais marginais: o caminho tortuoso para uma relação potencialmente frutuosa. In: ENCONTRO GALIZA PORTUGAL DE ESTUDOS RURAIS, 1., 1999, Bragança, Portugal. Anais... Bragança: Instituto Politécnico de Bragança; Instituto Universitário de Estudios e Desenvolvimento de Galicia, 1999.

CRISTÓVÃO, A.; TIBÉRIO, L.; ABREU, S. Restauração, turismo e valorização de produtos agro-alimentares locais: o caso do espaço transfronteiriço do Douro-Duero. Pasos, Santa Cruz de Tenerife, v. 6, n. 2, p. 281-290, 2008.

DGADR - DIREÇÃO-GERAL DA AGRICULTURA E DESENVOLVIMENTO RURAL. Fator de desenvolvimento rural. s.d. Disponível em: <http://bit.ly/2gc62Nm>. Acesso em: 5 dez. 2016.

DISSART, J.-C.; AUBERT, F.; TRUCHET, S. An estimation of tourism dependence in french rural areas. In: MATIAS, Á.; NIJKAMP, P.; SARMENTO, M. (Eds.). Advances in tourism economics. Heidelberg: Physica-Verlag, 2009. p. 273-294. 
Tourism in Analysis

FERREIRA, A. C. Formas de alojamento e impactos na sub-região Minho-Lima. 2004. Tese (Doutorado em Letras) - Faculdade de Letras, Universidade de Coimbra, Coimbra, 2004.

FIGUEIREDO, E. Um rural cheio de futuros? In: FIGUEIREDO, E. (Ed.). Rural plural. Castro Verde: 100 Luz, 2011. p. 13-19.

INE - INSTITUTO NACIONAL DE ESTATÍSTICA. Censos resultados definitivos região norte. Lisboa: INE, 2012.

. Statistical yearbook of the north region. Lisbon: INE, 2010.

. Study on municipal purchasing power. Lisbon: INE, 2009.

JESUS, L.; KASTENHOLZ, E.; FIGUEIREDO, E. Os promotores do ter: motivações, perfil, objetivos e ações de marketing. Revista Turismo \& Desenvolvimento, n. 17/18, p. 651-666, 2012.

JOAQUIM, G. Turismo e mundo rural: que sustentabilidade? In: CAVACO, C. (Ed.). Desenvolvimento rural desafio e utopia. Lisboa: Centro de Estudos Geográficos da Universidade de Lisboa, 1999. p. 305-312.

KOMPPULA, R.; RHODRI, T.; MARCJANNA, A. Developing rural tourism in Finland through entrepreneurship. In: THOMAS, ¡R.; AUGUSTYN, M. Tourism in the new Europe. Oxford: Elsevier, 2007. p. 123-133.

MCGEHEE, N.; KIM, K.; JENNINGS, G. R. Gender and motivation for agri-tourism entrepreneurship. Tourism Management, v. 28, n. 1, p. 280-289, 2007.

MESQUITA, A. V. Sistemas de distribuição no turismo em espaço rural: a região de Trás-os-Montes. 2009. Dissertação (Mestrado em Gestão e Desenvolvimento em Turismo) - Universidade de Aveiro, Aveiro, 2009.

MOREIRA, F. J. O Turismo em espaço rural: enquadramento e expressão geográfica no território português. Lisboa: Centro de Estudos Geográficos, 1994.

MURDOCH, J. Networks: a new paradigm of rural development? Journal of Rural Studies, v. 16, n. 4, p. 407-419, 2000.

PATO, L. Dinâmicas do turismo rural: impactos em termos de desenvolvimento rural. 2012. Tese (Doutorado em Turismo) - Universidade de Aveiro, Aveiro, 2012.

PORTUGAL. Ministry of Economy and Innovation. National strategic plan for tourism: fostering the development of tourism in Portugal. Lisbon: Turismo de Portugal, 2006. 


\section{TURISMO EM ANÁLISE vol 27, n.,3, Deacembro, 2016}

Tourism in Analysis

RIBEIRO, M.; MARQUES, C. Rural tourism and the development of less favoured areas: between rhetoric and practise. International Journal of Tourism Research, v. 4, n. 3, p. 211-220, 2002.

RIBEIRO, M.; MERGULHÃO, L. Turismo e desenvolvimento das regiões do interior: a perspectiva dos autarcas. In: CONGRESSO PORTUGUÊS DE SOCIOLOGIA, 4., 2000, Coimbra. Anais... Lisboa: APS, 2000.

ROBERTS, L.; HALL, D. Rural tourism and recreation principles to practice. Wallingford: Cabi, 2003.

SHARPLEY, R. Rural tourism and the challenge of tourism diversification: the case of Cyprus. Tourism Management, v. 23, n. 3, p. 233-244, 2002.

SILVA, L. A procura do turismo em espaço rural. Revista Etnográfica do Centro de Estudos de Antropologia Social, v. 11, n. 1, p. 141-163, 2007.

. Os impactos do turismo em espaço rural. Antropologia Portuguesa, v. 22/23, p. 295-317, 2005/2006.

Recebido em: 18/06/2016 (1 ${ }^{\mathrm{a}}$ versão) $09 / 08 / 2016$ ( $2^{\mathrm{a}}$ versão)

Aprovado em: 24/09/2016 